\title{
Why Children, Parrots, and Actors Cannot Speak: The Stoics on Genuine and Superficial Speech
}

\author{
Sosseh Assaturian \\ Penultimate Draft. Please cite the published version.
}

What kind of thing can speak? Consider the following four examples: (1) a pet parrot, who exclaims "Welcome home!" when you walk through the door, (2) a child saying "Dad!" while pointing at her father, (3) Margaret Hamilton uttering "I'll get you, my pretty, and your little dog too!" as the Wicked Witch of the West in The Wizard of $\mathrm{Oz}$, and (4) a friend asking, "What time is it?" when you're on the way to a gathering. According to the Stoics, only one of these examples counts as genuine speech. In particular, examples (1), (2), and (3), are cases of superficial speech, while (4) is an example of genuine speech.

Reconstructing the Stoic account of the difference between genuine speech and superficial speech is a difficult task, since it is not explicitly reported in our extant sources. A distinction between the genuine speech of adult humans and the superficial speech (or quasi-speech) of certain types of birds and children is attributed to Chrysippus in Varro's De Lingua Latina (Varro LL) VI.56. The case of parrots is discussed in a slightly more detailed testimony from Sextus Empiricus at Adversus Mathematicus (SE M) 8.275-276. In these texts, (1) and (2) are instances of superficial speech because non-rational animals and children lack the psychological constitution that is required for the proffering of genuine speech. As a result, the speech proffered by non-rational animals and children is superficial insofar as it sounds like, but somehow falls short of the genuine speech proffered by fully rational speakers.

The cases of the human-like speech of parrots and the speech of children dominates much of the scholarship in this area. ${ }^{1}$ If the above passages at Varro LL and SE M report a psychological condition for genuine speech - namely, that of rationality - then we are left wondering about the superficiality of the actor's speech in (3), which is absent from the reports in Varro LL and SE M. After all, actors, as humans, are rational agents, so the reasoning which explains the superficiality of the speech of the parrot and the child does not seem to apply to the actor. The picture is

\footnotetext{
${ }^{1}$ See for example Atherton (1993) p. $469 \mathrm{fn}$. 74, where the speech of parrots and children is discussed in the context of distinguishing between diction and speech, and Fögen (2014), which briefly discusses only the speech of parrots and children. The precedent for this is both textual and historical. First, as I discuss below, the manuscript of PHerc 307.9 is unstable and therefore ignored by some commentators. Second, throughout antiquity, we find a focus on discussions of animal communication and how it differs from human speech. In the philosophical context, for example, an interest in the difference between human speech and the utterances of non-rational animals appears as early as Theaetetus 189b190e, where Plato suggests that thought is inner speech, and that non-rational animals cannot think the way humans do. Aristotle also discusses the difference between the speech of non-rational animals and humans, claiming that although some non-rational animals are capable of proffering meaningful utterances, genuine speech is unique to humans (see especially History of Animals 4.9 535a-b, 8.12 597b, Parts of Animals 2.16 659b-660a, and Politics 1.2 1253a). The Hellenistic Schools later take up this discussion (see Lucretius 5.1028-90), sometimes with parrots as a focal point for theories of language acquisition, as discussed in Glidden (1994). The emphasis on the Stoic view of parrots in particular is so distinct that much later, Leibniz points out the Stoic origins of Locke's argument that parrots lack the psychology required for the production of genuine speech (Locke, Essay Concerning Human Understanding III.1.1-2 and IV.8.7, and Leibniz, New Essays on Human Understanding, Preface, 49).
} 
complicated by the fact that our evidence for the superficiality of the actor's speech is the unstable text of the Herculaneum Papyrus (PHerc) 307.9, which contains fragments of the Logical Investigations, a treatise on language and logic attributed to the third head of the Stoic school, Chrysippus. Only one edition of PHerc 307.9 includes a report about actors, in which Chrysippus claims that while an actor's recited lines express something (pragma), actors "do not swear, nor command, nor pray, nor question, nor inquire" - in other words, they do not perform speech acts. ${ }^{2}$ Commentators who have welcomed this addition have posited an explanation for the superficiality of the actor's speech which is different from the explanation for the superficiality of the speech of parrots and children. ${ }^{3}$ Accordingly, they offer an account of superficial speech that is not univocal.

My aim in this paper is to offer a reconstruction of the Stoic account of genuine and superficial speech. I show that not only is there an account of superficial speech that univocally explains (1), (2), and (3), but that taking (3) to be an instance of superficial speech based on PHerc 307.9 has interesting consequences for the Stoic view of language generally. The account of genuine and superficial speech I offer here challenges traditional assumptions about the entities at the heart of the Stoic theory of language-lekta. In particular, I offer some reasons to doubt the near consensus view that lekta are primarily entities that make utterances meaningful. ${ }^{4}$

I begin by disentangling a web of distinctions at Diogenes Laertius Lives of the Eminent Philosophers (DL) 7.57, between sound (phone), diction (lexis), and speech (logos), and between voicing (propheresthai) and expressing (legein). I show that in a strict sense, the primary objects of voicing are sounds, and that the primary objects of expressing are lekta. I argue that while the distinction between voicing and expressing is rooted in the fact that lekta, as incorporeals, cannot have causal powers, it is nevertheless true that in genuine speech, a lekton can indeed be voiced, and the objects of expressing can sometimes be items that are not lekta. The secondary objects of expressing, I argue, are the pragmata which are expressed by the actor at PHerc 307.9. Next, I show that both Varro LL and SE M report a rationality requirement for genuine speech, according to which

\footnotetext{
${ }^{2}$ In the texts that are included in their volume, Long and Sedley (1987) translate 'ta pragmata' as states of affairs. This translation is sometimes suggested in Frede (1994). Graeser (1982) translates the term as 'facts'. Beyond PHerc 307.9 and the various texts that identify pragmata with lekta, it is not clear when the term is being used in the quasi-technical sense I describe in this paper, and when it is instead being used in a very general sense to denote simply 'things'. The purpose of my paper is not to survey and give a systematic treatment of the various uses of this term in our Stoic sources. My focus is only on uses of the term in connection to language and lekta. In this context, I do not think that there is enough evidence to suggest that these entities are states of affairs or facts in the contemporary sense (see §3). To avoid unnecessary baggage, I leave the term untranslated. I take the quasi-technical sense of pragma to be somewhat nebulous, and understand it broadly as whatever the meaning of an utterance is, separate from a lekton.

${ }^{3}$ See, for example, Bronowski (2019a), which I discuss below.

${ }^{4}$ Lekton' is the verbal adjective from 'legein' - 'to say' or 'to express'. Although 'to say' is the more common English translation of legein, I translate legein as 'to express'. In ordinary English, 'to say' is too broad. For example, 'saying' can be synonymous with 'uttering', 'voicing', 'telling', or 'speaking'. For reasons that will become clear in my paper, the relevant sense of legein for the Stoics is 'to mean' or 'to express'. This usage is attested in the LSJ, including frequent uses in the Platonic dialogues. In addition, there are two translations of the verbal adjective lekton - one modal ('sayable', or 'what can be expressed') and one non-modal ('what is said', or 'what is expressed). Since I do not have the space here to address the conditions for the subsistence of lekta, I leave the term untranslated. The view that lekta are not primarily meanings is also argued in Bronowski (2019a), though the interpretation defended there also falls into the category of what I describe as the consensus view, since Bronowski argues that although lekta are not primarily meanings, when utterances are meaningful, it is because they express lekta.
} 
genuine speech requires a fully rational speaker. In these texts, the rationality of the speaker is partially explicated in terms of the capacity for internal discourse, which I refer to as rationality in the basic sense, and partially in terms of the ability to independently arrange words in an order proper to getting a particular lekton expressed. Instances of superficial speech violate this rationality requirement in one of two ways. The requirement is breached, as in (1) and (2), when the speaker is not fully rational, and for this reason, cannot independently produce or compose strings of utterances that express lekta. Or, it is breached as in (3), when the speaker experiences episodes in which she does not independently compose strings of words in service of expressing a lekton. Therefore, common to (1), (2), and (3) is that the rationality requirement, which dictates that the strings of words constituting an utterance are arranged together by an actively engaged mind, is breached. This breached rationality requirement results in the failure to express a lekton.

This account of the difference between genuine speech and superficial speech will turn out to have a few interesting consequences. First, the texts on superficial speech, along with the texts which report the type-differentiation of complete lekta, suggest that the expression of a lekton is constituted by the performance of a speech act. Genuine speech, then, is the performance of a speech act by way of expressing a lekton. Second, if I am right that genuine speech is the performance of a speech act, then counter to some interpretations of the relation between lekta and pragmata, PHerc 307.9 shows that lekta and pragmata are not always the same thing-for example, when actors proffer something meaningful without expressing a lekton. Rather, whatever pragmata are, they constitute the meanings of speech, and it is only because lekta are pragmata (and not the other way around) that lekta are also meanings. PHerc 307.9, then, explains how superficial speech can be meaningful - i.e. by expressing pragmata that are not lekta. Finally, the context of the report of the superficiality of the actor's speech in PHerc 307.9 suggests other episodic instances of superficial speech to which the account can be applied, including, for example, sentences in insoluble sophisms, such as those in the Not-someone sophism, the Liar paradox, and the borderline cases in a Sorites-series. In closing, my paper will suggest, against the near consensus view of lekta, that the Stoics are not primarily interested in linguistic meaning simpliciter. Rather, they are interested in the different things that language can do, and the conditions for doing them. Lekta primarily explain not what makes an utterance meaningful, but what makes an utterance an instance of genuine speech.

\section{Voicing and Expressing}

The Stoic distinction between an utterance (words or sentences, as vehicles, either written or spoken) and what the utterance expresses (a lekton) is well-attested. ${ }^{5}$ Lekta are not utterances.

\footnotetext{
${ }^{5}$ For example, in Long and Sedley (1987), Frede (1994), and Bronowski (2019b). See also the texts in fn. 7 below. By 'utterance' I mean words and sentences as the vehicles for a content, or to quote Atherton (1993), "a (permitted) sequence of elements" (p. 137). According to DL 7.56, the Stoics differentiate between written and spoken utterance (the latter includes sound and the former does not), but written utterances and spoken utterances are not terminologically distinguished. As Atherton notes, "the tacit assumptions are made that components of articulate (Greek) speech stand in a direct one-to-one correspondence with the letters of the (Greek) alphabet, and that vocal elements are simply strung together in a line to form utterances as letters are put together to form inscriptions." (p.137)
} 
They are what is expressed by an utterance. So, in "Mary had a little lamb," we have a string letters or sounds in words that are arranged in a certain order as the utterance, and something that is expressed by that string of letters and words, namely, that Mary had a little lamb. The distinction between utterance and lekton is marked by a difference in ontological status, as well as by the fact that they are the objects of different kinds of actions. ${ }^{6}$ Lekta are the primary, incorporeal objects of expressing, while utterances are bodies that are the primary objects of voicing.

The distinction between utterances and lekta reflects a difference at the level of ontology. At Seneca, Letters 117.13, DL 7.55-56, and DL 7.63, it is reported that utterances are bodies, or existents, while lekta are incorporeals, or subsistents. ${ }^{7}$ This ontological distinction marks an important fact about each of these two types of entities. Because they are bodies, utterances have causal powers. Spoken utterances are phonai, or sounds - they are air struck in a certain way by the impulses of the speaker. Hence, the causal element of speech is fulfilled by sound. Since lekta are incorporeals and not bodies, they are causally impotent. ${ }^{8}$

Utterances and lekta are also the objects of different types of actions. At DL 7.57, Diogenes reports that while utterances (as sounds) are voiced (propheresthai), lekta are expressed (legein):

(a) Sound (phone) and diction (lexis) differ because sound is noise, and diction is only what is articulate. Diction differs from speech (logos) because speech is always meaningful (sèmantikos), and diction can be meaningless (asēmos), for example, 'blituri', but speech never is. Expressing (legein) also differs from voicing (propheresthai), because sounds are what we voice (propherontai), but what we express (legetai) are things (pragmata) which actually turn out to be lekta. ${ }^{9}$ (DL $7.57=$ LS33A; SVF 3 Diogenes 20, part)

\footnotetext{
Whether the utterances are spoken or written is relevant for problems in the Stoic theory of language including the theory of ambiguity, but I will not differentiate between the two here, since my argument requires only the well-attested Stoic distinction between lekta and utterances (as vehicles, whether they are spoken or written). For the sake of simplicity, my argument throughout focuses on spoken utterance.

${ }^{6}$ By calling sounds and lekta 'objects' of voicing and expressing, I do not mean that voicing and expressing are powers that are differentiated by their objects in Plato's sense at Republic V 477a-480a, where seeing and hearing are powers that have, as their objects, sights and sounds, respectively. I have in mind something similar to the grammatical sense of 'object', according to which verbs have objects.

7 "What I see is a body, and it is to a body that I have directed my eyes and my mind. Then I say 'Cato is walking.' What I now express (he says) is not a body, but a certain enunciation about a body, which some call an effatum, others an enuntiatum, and others an edictum. So when we say 'wisdom' we understand something corporeal; when we say 'He is wise', we are speaking about a body." (Seneca, Letters 117.13 = LS33E) "An utterance is air that has been struck... and utterance is a body... For everything that acts is a body, and utterance acts when it proceeds from the speaker to the hearer." (DL 7.55-56 = LS33H; SVF 2.147, 2. Diog. 17, 18, 20, 2. Ant. 16, Arch. 6). "They say that a lekton is what subsists (huphistanai) in accordance with a rational presentation" (DL $7.63=$ LS33F; SVF 2.181, 183) where subsistence is a technical term assigned to signal the reality of incorporeals. Translations in this note modified from Long and Sedley (1987).

${ }^{8}$ Stoic ontology divides the supreme genus 'something' (tina) into body (sōma) and incorporeal (asōmaton). As Hahm (1977) p. 3 points out, causation is not explicitly stated as a defining characteristic of bodies that incorporeals lack, but it is clearly assumed in the texts. See for example Cicero, Academica $1.39=\mathrm{LS} 45 \mathrm{~A}$; SVF 1.90, SE M 8.263 =LS45B; SVF 2.363, and Nemesius 78,7-79,2 = LS45C; SVF 1.518.

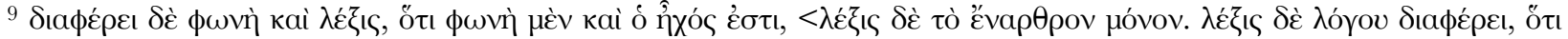

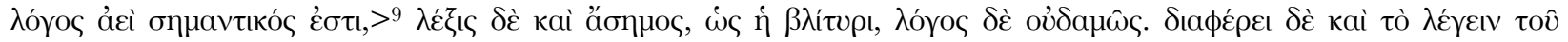

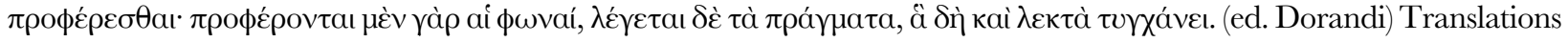
my own except where specified.
} 
In this text, we have on the one hand a three-fold distinction between sound (phone ), diction (lexis), and speech (logos), and a two-fold distinction between voicing (propheresthai) and expressing (legein). I begin with the three-fold distinction, which I take to be nested.

The distinction between sound and diction is that sound is merely a noise whereas diction is articulated noise (i.e. articulated sound). Since diction need not be meaningful, and the example that is given is of 'blituri', which is a meaningless articulated noise, mere sound must be meaningless and inarticulate noise. ${ }^{10}$ Next, DL explains that diction and speech are different because while diction is not always meaningful (as in 'blituri'), speech is always meaningful. It is plausible to think of these distinctions as nested, because first, at DL 7.56 (=LS33H; SVF 3. Diog. 20), diction is defined as articulate sound (phone engrammatos), while speech is defined as meaningful sound (phone semmantike) , so that both are explicitly described as kinds of sound. Second, neither diction nor speech should be possible without sound, insofar as the thing that is either articulate or meaningful is sound, and speech does not seem possible without diction (the articulate sound that is the vehicle for the meaning). In addition, at DL 7.62 (=LS30C; SVF 2.122, 3. Diog. 23), ambiguity is defined as diction that signifies two or more pragmata. If speech and diction did not overlap, an ambiguous utterance, as a meaningful, articulate sound, would not be called diction, but speech. However, while not all sound is diction and not all diction is speech, all speech is a kind of diction, and all diction is a kind of sound. Because the three-fold distinction is nested, some sound and some diction are meaningful or semantic (i.e. the sound and diction which overlap with speech), while some sound and some diction is not meaningful or non-semantic (i.e. the sound and diction which do not overlap with speech).

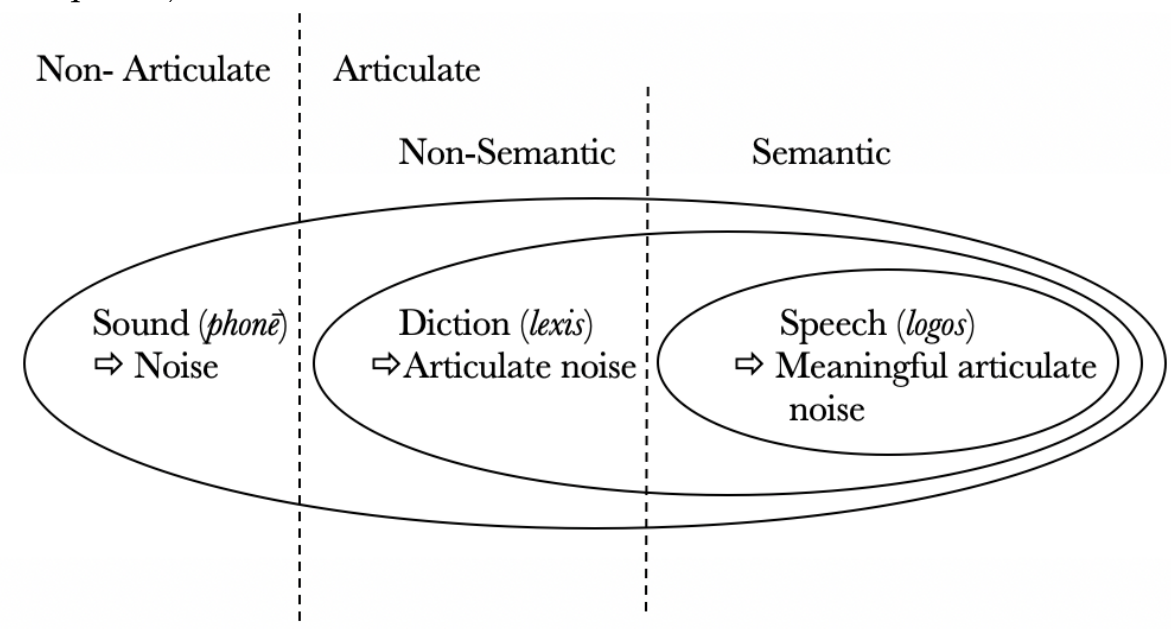

Fig. 1: The three-fold distinction between sound, diction, and speech

Next, we have the two-fold distinction between expressing (legein) and voicing (propheresthai). In (a), the distinction between these is explained by appeal to their objects. Sounds are what we voice, whereas what we express are pragmata, which, DL specifies, actually turn out to be lekta. Put

\footnotetext{
10 The same "nonsense" word appears at SE M 8.133 and Ammonius, De Int. 17,22. The description of 'blitur' as articulate but meaningless is consistent across all of the sources. See Blank (2014) p. 148 n. 154 for other nonsense words, such as 'knax' and 'skindapsos' in Ancient and Hellenistic discussions of language.
} 
differently, whether the sound is semantic or not, it is voiced, while what we express when we voice a meaningful sound is the lekton. This is confirmed at both DL 7.66-67 (=SVF 2.186) and SE M 8.71, which contain lists of the types of complete lekta and use 'expressing' (legein) when the object is a lekton. So far, then, what we express is strictly not the same thing as what we voice.

This is important given the ontological distinction between utterances and lekta. Because utterances and lekta are so intimately linked, we might think that in speaking (i.e. transmitting a lekton), one acts on a lekton and violates the condition that incorporeals are causally impotent. The distinction between voicing and expressing anticipates this worry. It tells us that what we do with words and what happens with lekta are different things. Lekta cannot be the primary objects of voicing, because we might think that this would be a way of acting on them, which would be in tension with their status as causally impotent. This is because, as we have seen, a sound is air that has been struck, and strikes the hearing organs. Voicing, then, has as its primary object something that is capable of being struck, and of striking. If lekta, as incorporeals, are causally impotent, then they cannot be the primary objects of voicing, for they cannot be acted upon by something else nor can they act upon something else. So, the distinction between voicing and expressing is one that is based on the ontological division between sounds as bodies, and lekta as incorporeals.

One potential problem for this interpretation appears at SE M 8.80 (=SVF 2.167):

(b) For 'to express' (legein) is, as the Stoics themselves declare, to voice (propheresthai) the sound (phōnen) capable of signifying the object conceived. ${ }^{11}$

In (b), far from being distinct from voicing, it seems that expressing is being defined in terms of voicing, so that expressing is a kind of voicing. How could this be the case if the objects of voicing and expressing are different? In (b), the object of the voicing is 'the object conceived' - the lekton. If speech is a kind of sound insofar as in an instance of speech, spoken sentences are vehicles for lekta, then it seems plausible that some kinds of voicing are also kinds of expressing - namely, when the sound is a vehicle for a lekton (as opposed to a meaningless noise). In this case, the objects of voicing are primarily sounds, while lekta are objects of voicing only under certain conditions, in an indirect sense - i.e. when the voicing is coextensive with expressing. The distinction between voicing and expressing as based on different objects still holds, for if the voicing were not a vehicle for a lekton, it would not also be a kind of expressing. ${ }^{12}$

How, then, does the two-fold distinction between voicing and expressing map onto the three-fold distinction between sound, diction, and speech? Because all diction and all speech are sound, they, too, are voiced. It is precisely because diction and speech are both sounds that in a strict sense, they cannot be expressed. I will revisit this point throughout my discussion.

\section{Lekta and Speech Acts}

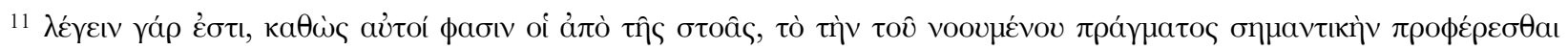
$\phi \omega v \eta ́ v . ~(e d . ~ M u t s c h m a n n)$

12 Cf. Bronowski's (2019a) broad vs. strict sense of voicing and of expressing (pp. 206-207). What is voiced in the broad sense are all noises, while the strict sense of voicing coincides with lekta. This roughly maps onto what I have described here. Bronowski's broad sense of expressing corresponds to the strict sense of voicing, while the strict sense of expressing, she maintains, has as its object "what significant sounds are significant of" or lekta themselves.
} 
Before we can use the distinctions in (a) to help us sort out the nature of genuine and superficial speech, more must be said by way of the role lekta play in speech.

There are several surviving lists of the types of complete lekta - purportedly, the meanings of complete expressions. ${ }^{13}$ At DL 7.66-67, the list consists of the assertible (axiōma), the question (erōtema), the inquiry (pusma), the command (prostaktikon), the oath (horkikon), the curse (aratikon), the supposition (hupothetikon), the address (prosagoreutikon), and the quasi-assertible (pragma homoion axiōmati). A slightly different list at SE M 8.71-73 (=SVF 2.187) includes assertibles, commands, inquiries, curses, and quasi-assertibles, but adds prayers (euktika) and omits questions, oaths, suppositions, addresses, and doubts. In Ammonius' Commentary on Aristotle's On Interpretation 2,26 ff. (CAG IV 5 2,9-3,6; SVF 2.188), the list includes assertibles, prayers, curses, addresses, doubts, oaths, suppositions, and quasi-assertibles. It omits commands, inquiries, and questions. ${ }^{14}$ The lists in Anonymus Coislinianus (An. Coisl.) include all of the types of complete lekta mentioned so far, with the addition of two types: the thaumastikon, which is used to express wonder, and the apokrisis or aphègematikon, expressed when answering an inquiry. ${ }^{15}$ The lists in Ammonius and An. Coisl. also include ekthetika, or positings, which occur only at the beginning of mathematical proofs. These are omitted from the lists in DL and SE. ${ }^{16}$

Schenkeveld maintains that there is a core list of ten types of complete lekta: assertibles,

${ }^{13}$ Lekta are divided into the complete (autotelēs) and incomplete (ellipe $)$ types. There is an open interpretive question about what it means for a lekton to be complete or incomplete. Here, I settle for DL 7.63's (= LS33F; SVF 2.181, 183) ambiguous formulation of the complete ones as having a complete expression and the incomplete ones as having an incomplete expression.

14 According to the schema in Schenkeveld (1985) p. 304, there is evidence in the Ammonius text of both inquiries and commands, but they are mentioned only when Aristotle's five sentence types are under discussion, and not in the list of the types of complete lekta at 2,26-3,5, though the claim at In An. prior. 2,3ff that the Stoics recognized eleven types of complete lekta only makes sense if they, along with questions are included. The text from Ammonius also interestingly suggests a classification according to which oaths, suppositions, quasi-assertibles, and doubts can be 'subsumed under' the assertible, the curse, or the address. There are reasons to doubt that this report is accurate and trustworthy. Ammonius explains that oaths, suppositions, and positings should be subsumed under the 'assertoric' because they are 'receptive of falsity and truth'. But assertibles are nowhere else (except in the late lists discussed in fn. 16 below) considered to be a genus, and oaths, suppositions, and positings are discussed as types of complete lekta in their own right - not as species of assertibles. Ammonius' claim that oaths, suppositions, and positings are truth-receptive might be the result of his own confusion about why oaths, suppositions, and positings are not truth-bearers, since prima facie, they do seem like they should be receptive of truth and falsity. However, many of our sources suggest that truthreceptivity is unique to assertibles (such as DL 7.66 =SVF 2.186 and SE M 8.71-72, and especially SE M 8.73-74). Finally, the dialectical context for this discussion in Ammonius is when he equates the taxonomy of Stoic complete lekta to the five Peripatetic sentence types. This equivalence on the part of Ammonius ignores the important and wellattested distinction between lekta and the sentences that express them. This confusion might be another reason why he believes that oaths, suppositions, and positings are truth-receptive.

15 CAG IV 5.xxii, 3-xxiii,9 and Aristotelis Opera IV Scholia, 93a21ff.

16 Positings are taken to be a later addition or sub-type that developed from a general type of supposition. In Schenkeveld (1985) p. 308-310, their absence from the list in DL is attributed to the lacuna at 7.66, since at 7.196, a treatise on ekthesis is attributed to Chrysippus. The lists in Prolegomena in Hermogenis 'peri staseōn' in Prolegom. Sylloge (ed. Rabe Rhet. Gr, XIV, 13,186,17-188,5) and Scholia in Aphthonium in Rhet. gr. (ed. Walz, II, 661, 25-662,26) also include all of the complete lekta mentioned above (including the wonder and the answer, the latter of which they call a diasaphetikon), with the exception of the positing and the quasi-assertible. Lists of complete lekta also occur with some variations in nomenclature in Theon Progymnasmata, in Rhet gr. II 87,13-90,17 and in Dionysius of Halicarnassus De compos. verb. c.8,1 p.32,6-13. However, the Stoics are not explicitly mentioned in these latter two texts. 
inquiries, questions, doubts, commands, oaths, prayers, addresses, suppositions, and quasiassertibles. ${ }^{17}$ I proceed with this list, for reasons which are mainly practical. First, my interest in this section is not to produce an exhaustive list of the types of complete lekta, but to establish the criterion by which types of complete lekta are differentiated. Moving forward with some core list is sufficient for achieving this. Second, these lists are nowhere introduced as exhaustive. There is no surviving evidence to suggest that the Stoics were even interested in producing an exhaustive list. And further, that there are some types of complete lekta that appear sparsely only across later sources (such as the wonder and the answer) is evidence that the lists underwent frequent revisions. In other words, we might take later developments of the taxonomy as evidence that the question about the types of complete lekta was one that was open. ${ }^{18}$

The underlying criterion for differentiating between the types of complete lekta is not explicitly reported, leaving it up to us as interpreters to extrapolate a criterion from the surviving lists. In the descriptions of the different types of complete lekta, both DL and SE appeal to what the speaker does in uttering a sentence that expresses the corresponding type of lekton. For example, DL 7.66 (= SVF 2.186) reports that "an assertible is that by expressing (legontes) which we make a statement (apophainometha), which is either true or false." ${ }^{19}$ At SE M 8.71-72 (=SVF 2.187), the lekton expressed by the sentence "The herdsman is like Priam's sons" "is an assertible, for in expressing it, we are either telling a truth or a falsehood." 20 According to these texts, an utterance expresses an assertible when a speaker does a certain sort of thing - i.e. asserts. Asserting is then explicated as expressing something that is true or false. The descriptions of each type in the two lists follow a similar pattern. An utterance expresses a question (erōtema) when the speaker performs some type of action - i.e. requests a yes or no answer. If the speaker requests some other sort of answer, and therefore, partakes in a different type of action, the sentence expresses an inquiry (pusma). ${ }^{21} \mathrm{It}$ expresses a command (prostaktikon) when the speaker performs another kind of action-i.e. orders or demands. It expresses an address (prosagoreutikon) when the speaker is using the utterance to address someone. This suggests that complete lekta are differentiated according to illocutionary function, so that each type of complete lekton has exactly one illocutionary function (i.e. it does exactly one type of linguistic thing) and the function of each type of complete lekton (i.e. the type of linguistic thing it does) is what delimits it from the others.

The relevance of illocutionary acts to complete lekta has been noticed, but generally has not

\footnotetext{
17 Prayers and curses are treated interchangeably, while wonders are treated as a type of quasi-assertible, and answers as a type of assertible. See Schenkeveld (1985) p. 303-310.

18 Schenkeveld (1985) p. 310 claims that this is evidence that the types that appear in later sources are not part of the core doctrine in the early Stoa.

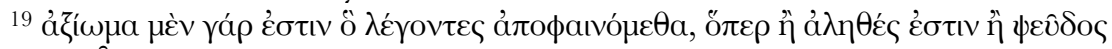

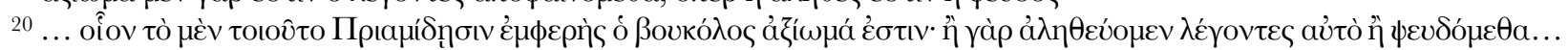
${ }^{21}$ One challenge is why asking (erein) and inquiring (punthanesthai) are different types of speech acts, given that the only difference seems to be that the speaker expresses a question when she requests a yes or no answer (or gesture), and an inquiry when she requests some other type of answer. One relevant motivation for the distinction might be that dialectical questioning in antiquity proceeds with a series of questions to which the respondent is allowed to answer only with 'yes' or 'no'. See Caluori (2018) p. 277. Accordingly, when engaged in dialectical questioning, the questioner is asking questions - engaging in one type of speech act - rather than inquiring - another type of speech act.
} 
been pursued or developed in any detail. ${ }^{22}$ While I will not be able to give this connection the full attention I believe it deserves here, it is nonetheless important as it is precisely the fact that speech acts are embedded in the background of the theory of lekta which explains puzzling features of the Stoic account of language, including why parrots, children, and actors do not proffer genuine speech.

The term 'illocutionary act' was coined by JL Austin in his influential How to Do Things with Words (1962) to describe those expressions whose utterance constitutes an action-or to quote Austin, cases in which "by saying something, we do something" like promising, or commanding, for example. ${ }^{23}$ Some notion of an illocutionary act or a speech act appears to be in the background of the taxonomy of complete lekta, as the criterion for type-differentiation.

That the different types of complete lekta are taxonomized with reference to linguistic doings coheres with DL's suggestion that the nomenclature of the types of complete lekta is derived from the verbs which correspond to what one does in expressing a lekton of a certain type: "The name assertible (axiōma) comes from asserting; for someone who says 'it is day' is thought to assert that it is day." 24 This report concerns only the assertible and its connection to asserting, but the principle generalizes. Just as the name 'axiōma', which is what is stated, derives from the verb 'axioun', which means 'to state', 'pusma' for an inquiry derives from 'punthanesthai' - 'to inquire', or the 'erotema', from 'erein', 'to ask'. This report is an indication that the Stoics take the etymological connection between the name of the verb and the name of its object to indicate something about how the two are related. In the linguistic context, the objects of different types of illocutionary acts are then differentiated from one another by reference to what it is that we do with each of them. In the above examples, these etymological ties are more explicit, as the -ma suffix for Greek nouns generally denotes the result or the object of the verb from which it derives. ${ }^{25}$ To repeat the example, the axiōma is the thing that is asserted, while the pusma is the thing that is inquired, and the erotema is the thing that is asked, etc. Even the types of complete lekta that do not contain the -ma suffix are nevertheless derived from their verb forms, which is signalled also by the -kon suffix, for example prosagoreutikon, from prosagoreuein. ${ }^{26}$ For the Stoics, this nomenclature is not merely accidental-it demonstrates a connection between the lekton and the linguistic action that is performed in expressing it. The term lekton, from legein, is also itself, predictably, an example of this schema, as the lekton is the very thing that is, in a strict sense, expressed.

Importantly, that some notion of an illocutionary act underlies the taxonomy of complete lekta need not entail that complete lekta are themselves illocutionary acts. For lekta are incorporeals, and construing them as acts of any sort would violate their status as causally impotent. ${ }^{27}$ Rather,

\footnotetext{
${ }^{22}$ I use 'illocutionary act' and 'speech act' interchangeably. For brief comments on lekta and speech acts, see for example Nuchelmans (1973) p. 65, Schenkeveld (1985) p. 311, Atherton (1993) p. 356, and Hülser (2012) p. 43.

23 Austin (1962) p. 109

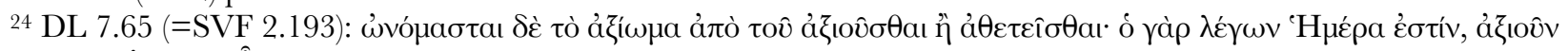

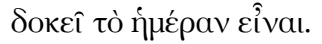

25 See Smyth, Greek Grammar $§ 841(2)$.

26 See Smyth, Greek Grammar $\$ 841(1)$.

27 That complete lekta are speech acts is sometimes asserted in Hülser (2012), for example at p. 43. However, on the same page, Hülser claims that complete lekta are merely governed by speech acts or illocutionary acts. My account
} 
the picture must amount to the following. First, a lekton is expressed because a speech act is performed; without speech acts, there are no lekta. Speech acts, then, help constitute complete lekta, but this does not entail that complete lekta are speech acts. It entails that complete lekta depend on speech acts. ${ }^{28}$ Second, any time a speech act is performed, a lekton has been expressed. The view so far, then, is as follows. When I express a complete lekton of a certain type, I utter a meaningful sentence and perform a speech act. But there is more to the story.

\section{Parrots, Children, and the Rationality Requirement for Genuine Speech}

One clue to the nature of superficial speech turns on the difference between non-rational animals and humans. Consider a parrot that has been trained to utter articulate sounds. This parrot, indeed, utters meaningful sentences. However, when a parrot utters the meaningful sentence, "What are you doing?" the parrot can hardly be said to have genuinely asked a question - i.e. performed a speech act. The text that reports, albeit indirectly, the Stoic distinction between genuine speech and superficial speech is SE M 8.275 (=LS53T; SVF 2.223):

(c) The Dogmatists say that humans differ from non-rational animals in respect of internal speech (endiathetos logos), not uttered speech (prophorikos logos). For crows, parrots, and jays utter articulate sounds. [Nor do humans differ from non-rational animals] in virtue of presentations simpliciter (for they too receive these) but in virtue of presentations created by inference and combination. This amounts to the human possession of the conception of 'implication' and one grasps the thought of sign because of this. For sign itself is of the following form: "If this, then that." Therefore, that there are signs also follows from the nature and constitution of the human. ${ }^{29}$

Sextus explains that the mere proffering of speech is not what accounts for the difference between humans and non-rational animals, for animals, too, can proffer articulate, meaningful utterances. Indeed, our parrot's "What are you doing?" does follow the syntactic rules that we normally associate with communicating meaningful speech. The difference, Sextus claims, lies in the psychology of humans relative to non-rational animals.

Stoic discussions of what is distinctive about humans - namely, rationality - have received considerable attention in the scholarship. Here, I only give a summary of the discussion as it

here more closely resembles the latter position. Cf. also Bronowski (2019a) pp. 231-242, where lekta are not speech acts, but "the difference of context determines a difference between two different kinds of lekta" (p. 241). But the formulation of context being the criterion which differentiates between two types of lekta is in tension with the core of Bronowski's argument that lekta do not depend on utterances, for she also holds that utterances are part of the context that determines the difference between two different kinds of lekta: "Only under certain conditions will an interrogative sentence properly express an interrogative lekton; only, that is, in a context in which a speaker wants to know something from someone (and requires an answer), will a question actually be a question.” (p. 244).

${ }^{28}$ As we will see, given the nature of thinking, "speech acts" need not necessarily be proffered speech.

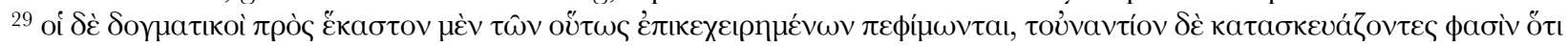

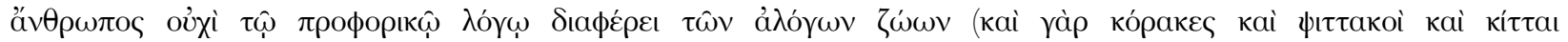

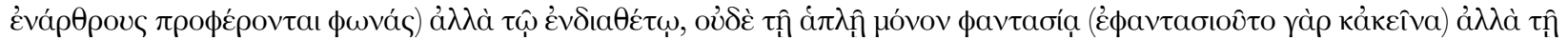

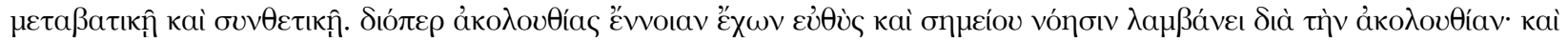

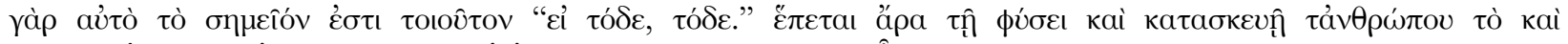

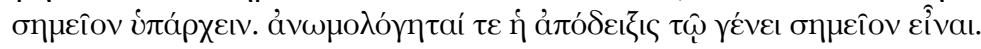


pertains to speech. Text (c) represents one testimony in which the differences between humans and other animals are that humans have internal speech (endiathetos logos) and presentations that are rational. ${ }^{30}$

The capacity for internal speech is often glossed as an ability to make statements to oneself. ${ }^{31}$ The idea seems to be that as humans, we have control over passing judgment on our presentations. The ability to reflect on and evaluate our presentations allows us to choose to assent to or to withhold assent from some lekton - the content of the presentation. ${ }^{32}$ Indeed, this is the locus of responsibility for the resulting action, and it requires a gap for deliberation between the presentation and the response. Internal speech occurs precisely in this gap for deliberation. Because internal speech allows us to evaluate our presentations, our presentations must be such as to be subject to evaluation. In (c), the rationality of our presentations consists in the fact that they are inferential (metabatike ) and compositional (sunthetike), where these two features together explicate how the contents of our presentations are constituted by lekta. ${ }^{33}$ If this is what constitutes a rational presentation, then minimally, a non-rational presentation can be negatively characterized as one that does not involve lekta.

This already suggests one reason why the parrot's speech is superficial and not genuine. Since parrots are non-rational, they lack the capacity for internal speech, and their presentations are not the type that are subject to evaluation - i.e. they are not propositional, where what makes a presentation propositional is that the lekton that inheres in it, arises from it. ${ }^{34}$ The parrot's presentations are not of the type to be subject to evaluation - they do not have propositional

30 The rational presentations that are unique to humans are also described at DL 7.49-51 (=LS39A; SVF 2.52, 55, 61). The notion of endiathetos logos, as internal speech, is also contrasted with logos prophorikos, or proffered speech throughout the surviving work of Philo of Alexandria, for example at De Migratione 83. In Mühl (1962), the distinction is taken to be Stoic in origin, and Fögen (2014) loosely attributes the distinction to Chrysippus, while Pohlenz (1939) maintains that the distinction was first formulated by the Academic philosophers, and Panaccio (1999) denies that it is specifically Stoic in origin. Throughout this paper, I have already been assuming that both animals and humans partake in logos prophorikos, and indeed, the project is to sort out how the human capacity for endiathetos logos, which is widely accepted as a Stoic notion in the scholarship, results in differences in the logos prophorikos of a non-rational animal relative to a human.

${ }^{31}$ For example, in de Harven (2019) and Long (1971).

${ }^{32}$ See also SE M 8.70 (=LS33C; SVF 2.187), DL 7.63 (=LS33F), and Epictetus, Diss. 2.18. 24-26.

${ }^{33}$ There are, of course, substantive questions about the nature of the relationship between lekta and rational presentations, as it is reported especially in DL 7.49-51 (=LS39A; SVF 2.52, 55, 61), DL 7.63 (=LS33F; SVF 2.181, 183), SE M 8.70 (=LS33C; SVF 2.187). Briefly, there are two main interpretive possibilities. According one interpretation, rational presentations have no propositional content of themselves. Rather, they are the way that lekta are perceived, so that lekta are not mind-dependent. For this interpretation, see for example Barnes (1993), Frede (1987), Ioppolo (1990), Kneale and Kneale (1962), Lesses (1998), Mates (1961), and Sorabji (1990). According to another group of interpretations, the content of a presentation is the way that the incoming information is conceived, so that lekta arise from and in consequence of rational presentations. See for example Brittain (2002), de Harven (2019), Shogry (2019), and Vogt (2012). I do not take a stance on this question here.

34 I use the language of a lekton 'inhering in' or 'arising from' a presentation in order to avoid question begging concerning whether presentations are causes or conduits of lekta, and the puzzle of whether lekta are mind-dependent. If (cf. the first group of interpretations above) lekta are independent semantic entities, then presentations have no propositional content of themselves. This results in the view that if all mental content is propositional and conceptual, then irrational animals (such as non-human animals and children) cannot have mental contents, leaving complex behaviours unexplained. The alternative is the second group of interpretations in fn. 33, according to which lekta are mind-dependent. 
contents, or otherwise involve lekta. Hence, the parrot's speech is not produced as a result of any sort of process involving rationality. This coheres with the view attributed to the Stoic Diogenes of Babylon at DL 7.55:

(d) While the sound [emitted by] an animal is the striking of air by impulse, human sound is articulate and sent forth by reason (apo dianoias), as Diogenes says, which comes to maturity at the age of fourteen. ${ }^{35}$

According to (d), the difference between the speech of a non-rational animal and the speech of a human is that only the latter results from reason. In addition to confirming the rationality requirement for genuine speech, text (d) suggests that a child's speech is also not produced from reason, since the formation of rationality is completed at the end of childhood.

The rationality requirement for speech in relation to non-rational animals and children is explicated in more detail in Varro LL VI.56's (=SVF 2.143) report of Chrysippus' view of genuine speech:

(e) 'To speak' (loqui) is said from 'place' (locus). Because the one who is said to speak now for the first time utters names and other words before being able to say them each in its own 'place' (locus); such a person, according to Chrysippus, does not speak (loqui) but it is as if he speaks (ut loqui), and that therefore, just as an image of a man is not a man, so too, in the case of ravens, crows, and children attempting to speak for the first time, their words are not words, because they are not speaking (non loquantur). Therefore, the one who speaks is one who, with understanding, puts each word in its own place (is loquitur, qui suo loco quodque verbum sciens ponit), and has then spoken forth (prolocutus) when he has, by speaking, expressed what he has in mind. ${ }^{36}$

Here, too, the psychology of the speaker determines whether what is proffered is genuine speech or 'quasi-speech' (ut loqui) - the latter of which we can think of as superficial speech, since it is still speech of a sort, but falls short of being genuine speech by virtue of the psychological conditions that are unfulfilled by the speaker. ${ }^{37}$ There are two features of (e) that are particularly interesting.

First, in (e), superficial speech belongs not only to non-rational animals, but also to children. This is completely in line with what we should expect if the requirement for genuine speech involves rationality, for as we saw in (d), children are not yet fully rational. For the Stoics, humans

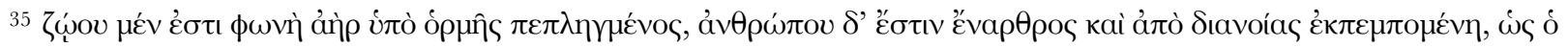

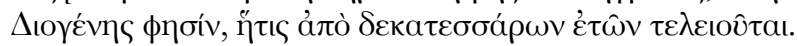

${ }^{36}$ Loqui ab loco dictum. Quod qui primo dicitur iam fari vocabula et reliqua dicit ante quam suo quique loco ea dicere potest, hunc Chrysippus negat loqui, sed ut loqui: quare ut imago hominis non sit homo, sic in corvis, cornicibus, pueris primitus incipientibus fari verba non esse verba, quod non loquantur. Igitur is loquitur, qui suo loco quodque verbum sciens ponit, et is tum prolocutus, quom in animo quod habuit extulit loquendo. (ed. Goetz and Schoell)

37 As Bronowski (2019a) p. 206 n. 23 points out, 'quasi' locutions are common throughout Stoicism. For example, concepts are called 'quasi-somethings' (hosanei tina) at DL 7.61 (=LS32C), and in the lists of complete lekta, we find entities that are 'quasi-assertible' ('pragma homoion axiōmati' at DL 7.66 = SVF 2.186 and 'pleona è axiōmata' at SE M 8.73). This locution signals superficial resemblances between two things - just as the quasi-assertible appears to be asserting something true or false, the resemblance between the quasi-assertible and the assertible is merely superficial. Here, too, the quasi-speaking of children and non-rational animals only superficially resembles the genuine speaking of fully rational agents.
} 
have the capacity for rationality from birth. Rationality requires having not only the proper store of concepts that are acquired through our interactions with the world, but as we saw in (c), it also requires understanding the inferential import of our concepts. While (c) does not explicitly discuss the status of children, we can fill in the account using details from Sextus' testimony. Because children do not yet have an adequate store of concepts, and because their understanding of the inferential relations between their concepts is incomplete, children are not fully rational. ${ }^{38}$ While their presentations may be at least partially subject to evaluation, children do not have the adequate store of concepts to reliably engage in internal discourse about them.

Second, and importantly, (e) explains why rationality is a requirement for the proffering of genuine speech. We are told that genuinely speaking is a matter of not only putting each word in its place, but putting each word in its place with understanding (sciens) - in expressing what one has in mind by placing the right words in the right order, and doing so in a certain way. In particular, in order to genuinely speak, one must first have something in mind (i.e. fulfill a basic rationality requirement) and also an understanding of how words can be used to express that thing. Genuine speech, then, requires that the speaker is rational in the basic sense of having the proper store of concepts, an understanding of the inferential relations between these concepts, and the capacity for internal speech. It also requires that the speaker understands how words properly connect to each other in a certain order to represent those concepts and inferential relations, such that those words can be used to express something. In genuine speech, the speaker independently places these words in the order that will properly get what they have in mind expressed. And given that the objects of expressing are lekta, these things which are expressed are assertibles, questions, commands, etc. The speaker understands how to structure language so that what is proffered is the particular assertible, question, command, etc. that she has in mind. Hence, it is only fully rational agents that have this capacity, and only fully rational agents that are able to express lekta and thereby perform speech acts. Genuine speech, then, is the performance of a speech act, which can only happen by way of expressing a lekton. This is why only rational agents can partake in genuine speech.

As (e) reports, non-rational animals and children might be able to proffer articulate utterances, but because parrots are not rational, and children are not fully rational, the words that help constitute their utterances, even if they are said in their proper places, are not said in their proper places with understanding. The point is that the sentences must not only follow syntactic rules, but that they must be placed in a particular order by the speaker themselves, and they must do so deliberately in service of getting something expressed - i.e. that which only the fully rational agent can have in mind. Since parrots and children do not have the proper psychological constitution, their utterances might be articulate and follow syntactic rules, but the words are not independently strung together by them in the way proper to getting something expressed. Parrots and children might, for example, learn certain sequences of words and proffer them, but those sequences will not be strung together by them independently, with an understanding of how each word in relation to the others properly expresses what it in fact expresses. This is indeed what Varro's statue simile

38 This is the view of the development of rationality in Cicero, Academica 2.21 (=LS39C). 
captures - the speech of parrots and children in relation to genuine speech is like the image of a man in relation to an actual man. The image of a man appears like the man, just as the utterances of parrots and children sound like the utterances of fully rational speakers. But the image of the man is not an actual man, just as the speech of parrots and children are not genuine speech. Due to the breached rationality requirement for genuine speech, parrots and children do not express lekta, and do not perform speech acts. The speech of parrots and children are therefore instances of superficial speech.

I pause here to consider how this picture so far fits in with the three-fold distinction in (a). Importantly, the parrot's "Welcome home!" and the child's "Dad!" are not only articulate, but meaningful. So, they are not examples of non-semantic diction. Recall that the example of nonsemantic diction (or articulate and meaningless sound) is 'blituri' - a nonsense word. The parrot's "Welcome home!" and the child's "Dad!" are importantly not nonsense. At the same time, they also cannot be considered speech as defined in (a). For speech is defined as articulate sound that is meaningful by virtue of expressing a lekton. Speech, as it is defined in (a) is what I have described here as genuine speech. This aligns with the account of superficial speech I have offered here, for the sense in which the speech of parrots, children, and actors is superficial because it sounds like genuine speech, insofar as it is articulate and meaningful, but it falls short of being genuine speech because no lekton is expressed. So, superficial speech and genuine speech are not two species of speech. Rather, superficial speech or quasi-speech falls short of counting as speech qua genuine speech. ${ }^{39}$ This is why superficial speech is an interesting problem - it does not fit into the taxonomy of (a).

However, the three-fold distinction in (a), along with the psychological picture I have described in this section, leaves us with some threads to untangle. First, if, as the consensus view maintains, lekta are themselves meanings, how can the utterances of parrots and children be meaningful without expressing lekta? Second, if the rationality requirement explains genuine speech, then the utterances of actors, as fully rational agents, should also count as genuine speech. However, a fragment from Chrysippus' Logical Investigations seems to deny this. Is there a univocal account of superficial speech?

\section{Lekta, Pragmata, and the Superficial Speech of Actors}

In order to arrive at a univocal account of superficial speech, we must confront the difficult text of Chrysippus' Logical Investigations from PHerc 307.9:

(f) Just as actors express (legousin) and signify (semmainousin) things (ta pragmata) but they do not swear, nor command, nor pray, nor question, nor inquire... ${ }^{40}$ (PHerc 307.9)

First, in (f), we find the familiar language of expressing pragmata. Recall that in (a), the distinction

39 Cf. Atherton (1993) p. 469 fn. 74, where the utterances of parrots and children are instances of "sometimes significant" diction which imitate genuine speech.

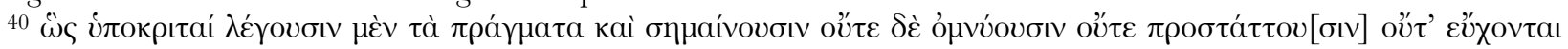

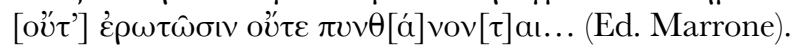


between expressing and voicing is explicated by appeal to their objects. We are told that the objects of voicing are sounds, whereas the objects of expressing are "pragmata, which actually turn out to be lekta." Earlier, I avoided a discussion of this mysterious phrase, as it represents an interpretive difficulty. Some of our sources suggest that 'pragma' is a Stoic term of art, though it is not clear what pragmata are and whether they are identical to lekta.

The significance of the term in (a) is that it is the pragmata which are lekta that are the objects of expressing, as opposed to sounds, which are the objects of voicing. This suggests that lekta are at least sometimes coextensive with pragmata. Similarly, in (b), expressing (legein) is defined as "pronouncing vocal sound significant of the pragma being thought." Since we know that the objects of expressing are lekta, this report is taken to suggest that pragmata are interchangeable with lekta. In the definitions of the assertible at DL 7.65 (=SVF 2.193) and Aulus Gellius Noct. Att. 16.8.1 (=SVF 2.194), the terms 'pragma' and 'axioma' (as a type of complete lekton) are used interchangeably. At DL 7.63 (=SVF 3. Crin. 2), it is suggested that pragmata and semmainomena, which later turn out to be lekta, are synonymous. ${ }^{41}$ Finally, as Atherton (1993) points out, at DL 7.190ff. (=SVF 2.13-18), we find a section of books dedicated to pragmata, which she says "almost without exception is a list of books concerning varieties of lekta." 42 The term pragma is also used to refer to incomplete lekta, as implied by the phrase "pragma autotelēs" to denote a complete lekton (and implying that there is a pragma that is not autoteles) at DL 7.65 (=SVF 2.193), and by the direct reference to the predicate as a type of pragma at DL $7.64(=\mathrm{SVF} 2.183)$.

There are two competing interpretations of the relationship between pragmata and lekta. One interpretation, which I will call the identity view, takes pragmata to be identical with lekta. The identity view is developed, for example, in Bronowski (2019a), Long (1971), and Long and Sedley (1987). ${ }^{43}$ According to the identity view, pragmata are states of affairs, and states of affairs are lekta. Another interpretation, which I will call the non-identity view, maintains that there are two kinds of pragmata - one kind which are said (i.e. lekta), and another non-lekta kind which can only be the contents of thoughts. ${ }^{44}$ According to this view, when thoughts are voiced, it is the pragmata which are lekta that are expressed, but when thoughts are not voiced, the contents of those thoughts are pragmata which are not lekta.

It is not clear, on the non-identity view, what the connection between the non-lekton pragma and the lekton pragma is supposed to be. First, if there are pragmata that are not lekta (because they are thought and not said) and pragmata that are lekta (when thoughts are said), then it seems that one cannot think assertibles, inquiries, or commands without saying them, since they are types of complete lekta. This is an unattractive consequence of the non-identity view. If all lekta must be said, then proponents of the non-identity view would need to categorize the content of the thought that

\footnotetext{
${ }^{41}$ Cf. Bronowski (2019a) pp. 93-94, where DL 7.43ff. is interpreted as reporting that both lekta and presentations (phantasiai) are types of sémainomena. I reject that presentations are semainomena and read DL as reporting not an ontological taxonomy, but a didactic one, in which the topic of presentations belongs to the topic of semmainomena. Presentations are nowhere else reported to themselves be sèmainomena, while lekta are called sèmainomena throughout our sources.

42 Atherton (1993) p. 252

43 Bronowski (2019a) pp. 214-216.

${ }_{44}$ Nuchelmans (1973) pp. 68-71 and Ax (1986) p. 201 n. 264.
} 
corresponds to "What time is it?" as a pragma and not a question, since if it were a question, it would be a lekton. So, the non-identity view confuses the connection between the thing thought and the uttering. ${ }^{45}$ Second, according to the non-identity view, speech is always involved in a pragma becoming a lekton, so that a non-lekton pragma is indeed still a thought content. However, despite how varied the interpretations might be, all of the surviving texts on Stoic rationality are clear about the fact that thoughts, in some way, involve lekta. ${ }^{46}$ The non-identity view therefore misinterprets how lekta are related to the thoughts of adult humans, which are rational. Third, the non-identity view confuses the distinction between voicing and expressing, because it implies that all there is to being a lekton is being voiced. Hence, if a content is not voiced, then it is merely a pragma and not a lekton. But, as we have seen, voicing and expressing have different objects, and the objects of voicing are only lekta in an extended sense (i.e. when the noise is not only articulate, but meaningful in a qualified way, which I will discuss below). Finally, if pragmata must meet certain conditions in order to be lekta, then the status of pragmata as items in the ontology is an issue that is not addressed in the texts. The non-identity views on offer, then, confront a series of problems that render them unattractive interpretations of how pragmata are related to lekta.

How does the identity view fare? First, understanding a pragma as a state of affairs and claiming that states of affairs are lekta seems to only work in the case of the assertible. For it is not clear what it would mean for a predicate, a question, or a command to be a state of affairs, though these are also called pragmata. An account of the relation between pragmata and lekta should include a coherent picture of non-assertive lekta. Second, if I am right that performing a speech act involves expressing a lekton, (f) appears to distinguish a pragma from a lekton. Proponents of the identity view must explain the apparent distinction between a pragma and a lekton in (f).

Text (f) is difficult. The fragments of Chrysippus' Logical Investigations in the PHerc arrive to us in a severely corrupted form. The particular line in (f) is an addition unique to Marrone's (1997) edition of PHerc 307, absent from both Hülser (1987) at FDS 4.2.698 and von Arnim (1905) at SVF 2.298. Given this, we might decide to set (f) aside as dubious. But what if we assume that the addition represents a genuine Stoic view? After all, there is precedent in the scholarship for a serious discussion of (f). So, it is worth seeing where pursuing it might take us.

Discussion of (f) in the context of superficial speech and the identity view takes place in Bronowski (2019a), where it is raised in service of her argument that a sentence is distinct from what it expresses (i.e. a lekton). For Bronowski, sentences express lekta only under certain conditions. For example, an interrogative sentence will only express an interrogative type of complete lekton "in a context in which the speaker wants to know something from someone (and requires an answer)". ${ }^{47}$ She argues that an important dimension of the Stoic account of the virtues of speech is therefore to master how to actually get a lekton expressed by speech. For Bronowski, the central

\footnotetext{
${ }^{45}$ Schenkeveld (1985) p. 313 suggests a way to make the connection more explicit, so that the pragma that is a question, for instance, contains the concept of a question: "in the cases of examples without a verb form the pragma itself contains not only the "thing thought" ... but also the thought of the addressing, or, in other cases, that of swearing an oath, etc. This means that the correlate of the physical sign...in the asomatic realm is the pragma... 'Atreus' son being addressed." But this requires special pleading with the view, as the texts do not support this modification.

${ }^{46}$ Cf. Bronowski (2019a) p. 216

${ }^{47}$ Bronowski (2019a) p. 244
} 
claim in (f) has to do precisely with the conditions under which a lekton can be expressed. On this view, fictional characters cannot express lekta because there is no such person there to express anything. Instead, she claims that the actor voices articulate sounds "but does not succeed in [expressing] anything." 48 But this raises a problem, for in (f), Chrysippus claims that the actor indeed does express something - he expresses pragmata. If we hold Bronowski to her commitment to the identity view, then it seems like her view of (f) should be that actors do express lekta. However, she denies that they do. The identity view, therefore, cannot offer a coherent interpretation of (f), for if pragmata are lekta and actors express pragmata, then actors express lekta. But if the expression of a lekton is required in order to swear, command, pray, question, or inquire, and actors do not do any of these things, then what they express cannot be a lekton. ${ }^{49}$ In (f), it is not only the case that expressing can have an object that is not a lekton, but it is also suggested that the expression of a pragma can be separate from the expression of a lekton. With the speech acts model of lekta in the background, (f) renders the identity view implausible, for if pragmata can occur separate from lekta, then these two terms are not used to refer to the same thing, and lekta are not identical to pragmata.

Bronowski (2019a) compares the speech of an actor to the speech of parrots and children, claiming that like parrots, actors voice significant sounds but do not succeed in saying anything. Nevertheless, she claims that "something more than parroting is taking place at the theatre." 50 She does not explain what she takes to be difference between the cases of the parrot and the child on the one hand, and the case of the actor on the other. Presumably, the difference for her is that while the parrot and the child voice significant sounds, the actor, as Chrysippus claims, expresses something. While the fictional character, as a figment, is incapable of "the deep, structural understanding of [expressing]" and cannot even voice sounds, it seems that the actor is indeed capable of this, as a fully rational human being. This already marks a difference with both the parrot case and the child case, as parrots are non-rational animals and children are not fully rational. Her discussion ends on a somewhat unsatisfying note, suggesting that what Chrysippus is really doing in (f) is raising a puzzle about the nature of the superficiality of the actor's speechnot presenting a solution. But a closer look at (f) shows that Chrysippus is neither raising a puzzle about the actor's speech, nor explicitly presenting a solution to some purported puzzle about the nature of the actor's speech. Rather, the context of (f) reveals that the superficiality of the actor's speech is being taken for granted in service of a larger discussion pertaining to sophistical arguments.

Before we can get there, we need to sort out Chrysippus' use of legein (as opposed to propheresthai) in (f). So far, we have seen that the objects of legein are lekta. In (f), the objects of legein are pragmata. The obvious question, then, is whether the use of legein in this text is evidence that lekta

\footnotetext{
48 Bronowski (2019a) p. 243

49 Although Bronowski (2019a) is committed to the identity view at p. 216, she also asks what the pragmata are that are expressed by the actor in (f) at p. 242. She briefly raises the possibility that a pragma is "a propositional content, which is yet to be formulated in a statement, a question, a command, and so on..." but dismisses this on the grounds that the sentences uttered by the actor have the characteristics of a statement, question, command, etc. She does not, as far as I can tell, pursue the question further. It is puzzling that her earlier discussion of the identity between pragmata and lekta does not reappear here.
}

50 Bronowski (2019a) p. 243 
are identical to pragmata. But we have already seen that if we understand pragmata as identical with lekta, and we substitute 'ta pragmata' in (f) with 'lekta', we are forced to read Chrysippus as incoherently claiming both that actors express lekta and that actors do not express lekta, for performing a speech act is the expression of a lekton.

It seems that the view described in (f) must, rather, be that there are pragmata that are lekta and pragmata that are not lekta. But the difference between the two will not be the difference that is endorsed by adherents of the non-identity view - i.e. that the former are lekta by virtue of being said and the latter are thought contents that are not said and hence, not lekta. ${ }^{51}$ Rather, the alternative is to understand pragmata as sometimes coextensive with lekta, and to relax the conditions for expressing as we did with voicing. In (f), while actors may utter their lines on a stage, and while those utterances are meaningful, insofar as the audience can (assuming they understand the language that is being spoken) grasp those meanings, actors do not actually utter sentences that express lekta, because there is more to expressing a lekton, than merely uttering a sentence that is meaningful.

Recall that genuine speech is constituted by the performance of a speech act, which only a fully rational agent is capable of, by means of independently and deliberately arranging words into the sequence proper to getting what they have in mind expressed. This arrangement must, as Varro describes in (e), be done "with understanding". I have already discussed how parrots and children breach this requirement. Parrots and children proffer meaningful utterances, but because the background psychological condition is not met, they cannot be said to perform speech acts, and hence, cannot genuinely speak. Similarly, when an actor is reciting lines, the actor is not deliberately and independently arranging words into the order proper to expressing something. These words are already arranged in a certain order by someone else, and memorized by the actor. Hence, like the parrot and the child who have learned pre-determined sequences of words, the actor, too, memorizes the lines that are proffered on stage. The actor does not, in that moment, consciously deliberate on what particular sequence of words will express her own thoughts. She does not select those words herself, nor does she compose anything. She utters sequences of words that have been selected and composed for her. Therefore, the actor's speech, like the speech of the parrot and the child, appears like genuine speech, but is merely superficial. Although the actor herself might fulfill the rationality requirement, her speech while acting does not fulfil the background psychological requirements for expressing anything.

Consider the following example, in line with (3) at the beginning of this paper. When Margaret Hamilton exclaims, "I'll get you, my pretty, and your little dog too!" as the Wicked Witch of the West in The Wizard of $O z$, perhaps she is "threatening" something in some attenuated sense, but according to Chrysippus, like the parrot and the child, she utters a meaningful, articulate

\footnotetext{
${ }^{51}$ One way for the non-identity view to make sense of $(\mathrm{f})$ is to claim that the actor does express pragmata that are lekta, but that there are lekta that are not any of the types that are described by DL or SE, or indeed in any of the other texts which report the different types of complete lekta. One candidate would be to construe reciting lines as a kind of complete lekton. But if, as the non-identity view maintains, all there is to a pragma becoming a lekton is the saying, then it is difficult to see how the actor fulfills the condition of saying pragmata, but does not thereby say any lekta, for the saying itself should render the pragma a lekton. Text (f), then, backs both the non-identity view and the identity view of the relation between pragmata and lekta into a corner.
} 
sequence of words that have been arranged by the script-writer. As much as her utterance might seem like a threat, she is not genuinely threatening anyone. No speech act is being performed, and hence, as Chrysippus suggests in (f), no lekton is being expressed. This is the sense in which the actor's speech does not count as genuine speech.

But there is something importantly different about the superficiality of the actor's speech while reciting lines and the superficiality of the parrot's and the child's speech. In particular, an actor, as a fully rational human, is capable of genuine speech when not reciting lines, whereas the parrot and the child are not capable of genuine speech. The actor's breach of the rationality requirement is therefore episodic, insofar as it occurs only in certain circumstances - i.e. in the theatrical context, when she is reciting lines in character. Outside of this context, the fully rational human who is perhaps an actor by occupation or by hobby, does indeed proffer genuine speech. Importantly, the speech of the parrot and of the child is a breach of rationality non-episodically. By virtue of the non-rational nature of the parrot, and the not-fully-rational psychology of the child, parrots and children are not capable of proffering genuine speech.

This suggests, against what is the near consensus view of lekta as meanings, that in order for the utterance that is voiced to express a lekton, it must do more than merely be meaningful or significant. A lekton is expressed not only when the utterance is meaningful, but when the speaker performs a speech act - when the speaker genuinely speaks. Superficial speech is therefore meaningful speech that expresses something - a pragma - but does not express a lekton.

In (f), then, Chrysippus claims that the utterances of actors do signify and express pragmata, but the utterances don't actually amount to the performance of a speech act. We can supplement his reasoning for this claim as implying that no lekton is expressed by an actor reciting their lines, because while acting, the actor cannot be said to perform a speech act. The meaningfulness of the actor's speech, and indeed of the speech of the parrot and of the child, is explained by the fact that whatever pragmata are, they always make utterances meaningful. Recall that in (a), the objects of expressing are pragmata, which turn out to be lekta. Since an utterance that expresses a lekton cannot be meaningless, all lekta are pragmata, but not all pragmata are lekta. There is therefore no tension in simply using 'pragma' in place of 'lekton' as some of our sources do, as long as we understand this use of 'pragma' as qualified. If we understand the phrase in (a) as specifying that the objects of expressing are not pragmata in an unqualified sense, but specifically the lekton as a kind of pragma, we can make sense of why Chrysippus would claim that the utterances of actors signify and express pragmata while no lekton is expressed. The recited lines of the actor, as well as the speech of parrots and children still have meanings, after all, even if they do not constitute speech acts. 


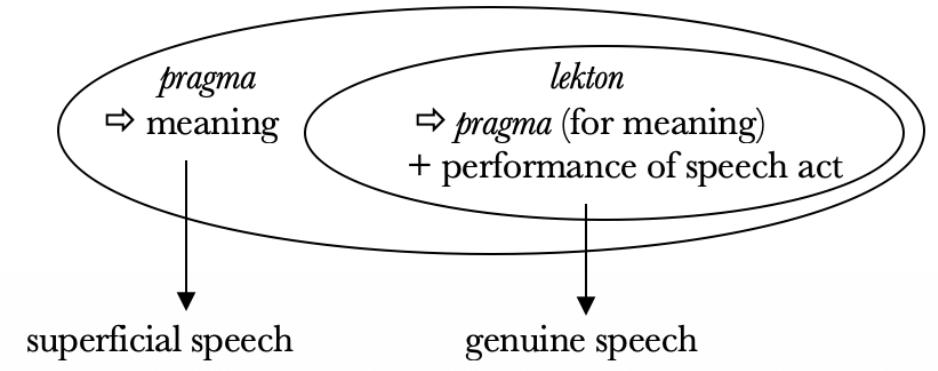

Fig. 2: The relation between lekta and pragmata and their roles in superficial and genuine speech

There is one additional thread to untangle in (c), which is that legein has as its object a pragma. I argued that expressing was differentiated from voicing by virtue of having lekta instead of sound as an object. If we take seriously the legein of (c), my earlier interpretation of expressing as having only lekta as its objects must be loosened, so that Chrysippus is not contradicting himself. In the case of expressing, recall that distinguishing expressing from voicing preserves the status of lekta as causally impotent. For one might plausibly view an act of communication as a way of acting on or being acted upon by lekta - as a transfer or an exchange. The Stoic response is to distinguish voicing from expressing, so that the causal component of speech is not the content, which is an incorporeal, but the vehicle, which is a body. The distinction, then, between voicing and expressing is, indeed, one that is primarily drawn along the lines of the objects of each type of action. Call this voicing ${ }^{\mathrm{a}}$ and expressing ${ }^{\mathrm{a}}$. But in practice, we can see that there is an extended, informal, and secondary sense in which even lekta can be voiced (i.e. when they are the contents of spoken utterances) and a derivative sense in which items that are not lekta (i.e. pragmata that are not lekta) are expressedi.e. as the meanings of well-formed, articulate utterances, which nevertheless do not fulfill the psychological conditions for expressing a lekton. Call these voicing ${ }^{\mathrm{b}}$ and expressing ${ }^{\mathrm{b}}$.

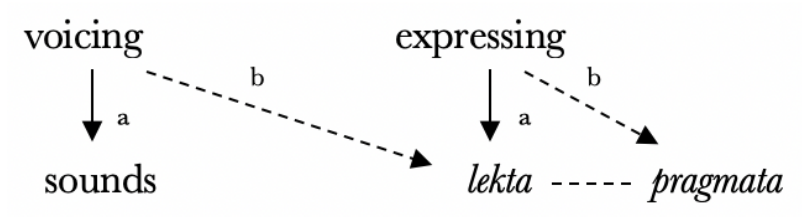

Fig. 3: The relations between voicing ${ }^{\mathrm{a}}$, expressing ${ }^{\mathrm{a}}$, voicing ${ }^{\mathrm{b}}$, and expressing ${ }^{\mathrm{b}}$, and their objects Expressing $^{\mathrm{b}}$ a pragma, then, is what makes the utterance meaningful, but expressing ${ }^{\mathrm{a}}$ a lekton is what makes the speaker engage in a speech act - to assert, to command, to ask, etc. The latter is what it is to genuinely speak.

\section{Other Instances of Superficial Speech?}

The fact that one thing explains meaning (i.e. pragmata) and another thing explains genuinely speaking (i.e. the lekton) has philosophical utility beyond explaining the superficial speech of actors, parrots, and children. The context of (f) helps identify other instances in which a pragma is expressed without the expression of a lekton. The text directly preceding (f) does not survive, but the text 
immediately following it does. For this, I turn to Hülser's edition of the manuscript, which reads:

(g) ... up to what point one must continue to respond (hupakouein) the same way is difficult, just like (kata) the Sorites series (ton para mikron logon). Similarly, when one must make a cut (temein) with regard to one's answer, it is likely that this is also not possible. $^{52}$ (PHerc. $307.9=\mathrm{LS} 37 \mathrm{G}$; SVF 2.298, part)

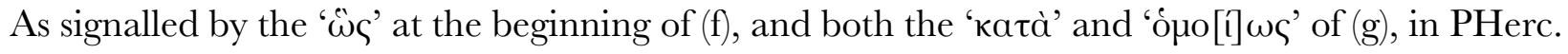
307.9, far from presenting a puzzle with no solutions, Chrysippus brings in the superficiality of the actor's speech in order to emphasize a similarity between the speech of actors and some feature of a Sorites series. What could the speech of actors and a Sorites series possibly have in common?

The Sorites paradox was presented in the form of a series of questions and answers. Bobzien (2002) produces the following example:

'Does one grain of wheat make a heap?' - 'No' - 'Do two grains of wheat make a heap?' 'No'-'Do three?' - 'No' - etc. If the respondent switches from 'no' to 'yes' at some point, they are told that they imply that one grain can make a difference between heap and nonheap, and that's absurd. If the respondent keeps answering 'no', they'll end up denying e.g. that 10,000 grains of wheat make a heap. And, they are told, that's also absurd..$^{53}$

As she remarks, it is not clear what 'cutting' (temnein) means in sophisms like the Sorites, but it does appear in the context of one's answers in Sorites questioning. In (g), Chrysippus suggests that cutting is likely not possible. Bobzien advances the following interpretation of why cutting is not possible in a Sorites questioning: "When one comes to the borderline cases in a Sorites-series, it isn't possible to answer the $i$-th case with 'yes', and the $(i+1)$-th case with 'no'."54 The idea is supposed to be that cutting is impossible in the series of answers because "in borderline cases there is no fact of the matter" and hence, at least some of the cases have no truth value, and therefore do not correspond to an assertible - the type of lekton that has a truth value. ${ }^{55}$

She maintains that this strategy seems to have been exploited in special cases, such as insoluble sophisms. Take, for example, the Not-someone (outis) sophism, which has the form of two premises and a conclusion:

If someone is in Athens, that one is not in Megara.

Now man is in Athens.

Hence, man is not in Megara. ${ }^{56}$

Here, the second premise would not express an assertible, "since 'man' is a generic term, and to

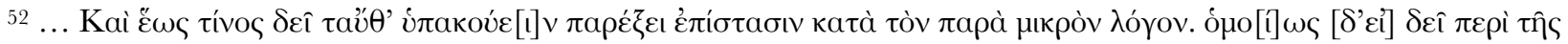

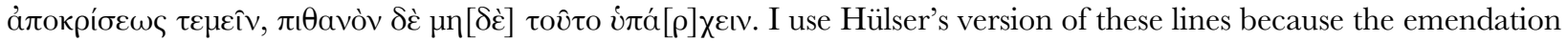

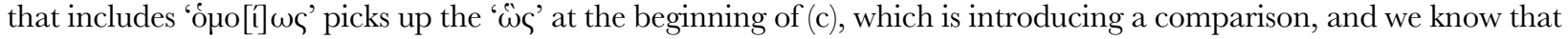

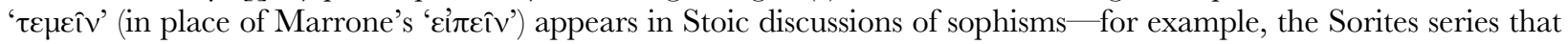
is mentioned in this text.

${ }^{53}$ Bobzien (2002) pp. 217-218. The example is based on the discussion at Galen, Medical Experience XVI.1-2 and XVII.102. See her p. $217 \mathrm{fn} .3$ for a short discussion of different possible forms of the Sorites.

${ }^{54}$ Bobzien (2002) p. 224

55 Bobzien (2002) p. 224

${ }^{56}$ See Simplicius, On Aristotle's Categories 105,8-16 (=LS30E; SVF 2.278, part) 
[presentations] where a predicate designed to be predicated of individuals is predicated of a generic term, no [assertible] corresponds." ${ }^{57}$ Another example is the Liar paradox, in which the sentence "I am speaking falsely" does not correspond to an assertible because it is neither true nor false. ${ }^{58}$ Bobzien also appeals to the Stoic view of declarative sentences with an "empty" demonstrative in the subject term, such as "This one is dead." The definite assertible corresponding to this sentence ceases to subsist when the object of the demonstrative reference has died. ${ }^{59}$ However, the sentence still exists, and indeed, it is meaningful.

Although this is not Bobzien's strategy, a distinction between pragmata and lekta indeed explains how in these cases, sentences can be meaningful without expressing lekta. The aim of Bobzien's paper is to challenge Williamson's (1994) claim that Chrysippus pioneered the epistemic response to the Sorites. ${ }^{60}$ What follows from denying that all declarative sentences express assertibles is that against Williamson, Chrysippus' commitment to bivalence will not, by itself, result in a commitment to the epistemicist position. Hence, when responding to Sorites questioning, Bobzien contends that one must "pull up one's horses" not at the precipice of falsity, but at the precipice of absurdity, where falling into absurdity is assenting to something evidently false. ${ }^{61}$ One consideration is that even if certain sentences in insoluble sophisms do not express assertibles (because they are not true or false), the sentences are also not total nonsense. Compare, for example, "Fifty-one is few, but fifty-two is many", or "Man is in Athens" with "blituri". Something rather different is happening with the first two sentences, insofar as they follow syntactic rules using words that ordinarily denote certain items, so that we can still, in some basic sense, understand them, whereas "blitur" is total nonsense. Indeed, sophisms are ultimately deceiving, not because they employ utterly meaningless sentences as though they have meanings, but because they employ meaningful sentences that are not truth evaluable, as though they can in fact be true or false. It is not treating these sentences as though they are meaningful that ensnares us in absurdity. Rather, the absurdity consists in the assenting, since the sentences do not express anything truth evaluable.

That borderline cases in a Sorites-series, sentences with empty demonstratives, or premises in sophisms do not express assertibles does not, of course, by itself entail that they do not express any complete lekta at all. But if these cases did express a complete lekton, it is not clear what type of complete lekton they would express, since our lists do not report one that corresponds to a sophism, or to a sentence with a demonstrative subject term referring to a non-existent body. This is precisely what the actor simile in PHerc. 307.9 is meant to illustrate. The superficial speech of the actor is meaningful and expresses a pragma, but does not express a lekton. So too, in $(\mathrm{g})$, borderline cases in

\footnotetext{
57 Bobzien (2002) p. 221

58 Bobzien (2002) p. 221, though she also entertains that this sentence might express an assertible that is exempted from bivalence. The proposal that the sentence does not correspond to an assertible because it is neither true nor false is favourable. First, it allows us to hold Chrysippus to a universal commitment to the Principle of Bivalence instead of interpreting him as in some cases ready to eschew the Principle. Second, it is unclear what it would mean for an assertible to be exempted from bivalence, since our sources define assertibles as items that are either true or false. See for example DL 7.65 (=LS34A; SVF 2.193), DL 7.69, and SE M 8.74 (=LS34B; SVF 2.187).

59 See Alexander of Aphrodisias In Ar. An. Pr. 177.27-178.1 (=LS38F; SVF 2.202a)

${ }^{60}$ Epistemicism is the view that a vague sentence in a borderline case expresses a true or false proposition, but we cannot know its truth value. See Williamson (1994).

${ }^{61}$ Bobzien (2002) pp. 225-226
} 
a Sorites-series are meaningful because they express pragmata, but are not truth evaluable, because they do not express a lekton. Because no lekton is expressed, it is impossible to make a cut in a Soritesseries. The same holds of the problematic premises in the Not-someone sophism and the Liar paradox. These sentences are meaningful and express pragmata, but do not express a lekton. ${ }^{62}$

Whether these sentences are also instances of superficial speech is difficult to adjudicate. If genuine speech is always the expression of a lekton, then it seems as though these should not count as genuine speech. At the same time, if superficial speech is marked by a breached rationality requirement, we might wonder if borderline cases in a Sorites series, sentences in a sophism, and sentences with "empty" demonstratives indeed fall into this category. Again, the proximity of the actor case and the episodic nature of the superficiality of her speech can help us here.

First, as a part of sophism, we might think that the respondent is being asked to entertain a conceptual confusion, which is a breach of rationality. For example, in entertaining "Man is in Athens" one entertains a predicate being arranged with an item that it is not meant to be arranged with. Similarly, if the respondent of a Sorites-questioning is entertaining "Fifty-one is few, but fiftytwo is many" we might think that what she is entertaining involves a confusion of the concepts 'few' and 'many'. Second, recall that (e) explicates rationality in the context of speech as consciously composing a series of words in a structure proper to getting the lekton the speaker has in mind expressed. In the above examples, the words that are being placed in a certain arrangement are not in the service of expressing a lekton. So, even if the composition is independent or deliberate, it is not being done in order to express a lekton.

Borderline cases in a Sorites series, sentences in a sophism, and sentences with "empty" demonstratives, then, are indeed cases of superficial speech. Similar to the actor case, the rationality requirement is breached episodically. Indeed, this might be one reason why this case and not the parrot or the child, is raised by Chrysippus as one that bears similarities to the Sorites. Hence, the distinction between pragmata and lekta and the characterization of superficial speech as speech that expresses a pragma but not a lekton can be used to analyse sophisms as sets of sentences that exemplify superficial speech. The philosophical utility of the distinction is therefore threefold. It provides the machinery for explaining what is distinctive about the speech of fully rational humans in ordinary contexts (as opposed to the speech of non-rational animals, children, and actors). It also allows the Stoics to offer solutions to sophisms, and to account for linguistic

\footnotetext{
${ }^{62}$ It is worth raising the following worry. According to the traditional view of lekta as mere meanings, assertibles are lekta that are the bearers of truth. As such, assertive meanings are truth conditions. One potential problem with separating pragmata and lekta, and claiming that pragmata are meanings, but that only assertibles are truth bearers is that meanings are no longer truth conditions. In response to this, we might speculate that since assertibles must be pragmata, the pragmata constitute what it would take for the assertible to be true if the pragma were part of the lekton. So, pragmata are only truth conditions if they are coextensive with assertibles, since only assertibles can be truth bearers. I have been using the speculative language of lekta being 'identical to' pragmata, of lekta 'being' pragmata, or lekta being 'coextensive' with pragmata (and not the other way around). This language is admittedly not informative, and explicating exactly what the relation is between pragmata and lekta would require an account of the structure of lekta, which I cannot give here. I do think that there is a plausible story to be told, in which whatever pragmata are, they sometimes help constitute lekta, and they do so by means of undergoing unification. One candidate for the unifying element is the speech act, which gives the pragmata the character of being lekta - of being the kind of thing that can be true or false, that can request a 'yes' or 'no response, etc.
} 
phenomena such as declarative sentences that contain certain kinds of demonstratives that do not refer to anything. We can speculate about other examples that the distinction can help explain, such as the utterances of a language teacher in a classroom. While teaching common English sentences, the teacher might utter "It is raining," without thereby asserting that it is raining. All of these, unlike the case of genuine speech, involve a speaker expressing a pragma without expressing a lekton.

\section{Conclusion}

We set out searching for an account of superficial speech that would uniformly explain why the Stoics deny that the speech of actors, children, and non-rational animals such as parrots are instances of genuine speech. I have shown that through a regimented series of distinctions between sound, diction, and speech, between voicing ${ }^{\mathrm{a}}$, expressing ${ }^{\mathrm{a}}$, voicing ${ }^{\mathrm{b}}$, and expressing ${ }^{\mathrm{b}}$, and between pragmata and lekta, the Stoics establish the conditions for genuine speech. Genuine speech, they argue, is beholden to a rationality requirement. First, the speaker must be a fully rational agent in the sense of being capable of internal discourse. Second, the speaker must understand how words can be arranged in a structure proper to getting what she has in mind expressed, and she must independently arrange them in accordance with her understanding. Given that the primary objects of expressing are lekta, in instances of genuine speech, it is lekta that are expressed. And since lekta account for the performance of speech acts, genuine speech is the performance of a speech act. All instances of genuine speech are therefore instances of asserting, asking, inquiring, commanding, etc. Hence, superficial speech is characterized by instances of speech in which the rationality requirement is breached either episodically or non-episodically. For in the speech of the parrot, the child, and the actor performing in the theatrical context, in (1), (2), and (3) at the beginning of this paper, the words that are voiced are not placed into a deliberate arrangement by the speaker independently, and what is expressed is not sent forth from reason, but from impulse. Superficial speech, then, does not express ${ }^{\text {a }}$ - that is, no lekta are expressed in instances of superficial speech, and the speaker does not perform a speech act. Rather, superficial speech, insofar as it is meaningful, expresses only pragmata. After completing the account of superficial speech, I used PHerc 307.9 to explore other possible instances of superficial speech, and I showed that among others, sentences in insoluble sophisms, including in the Sorites series, the Not-someone sophism, and the Liar paradox, as well as sentences with empty demonstratives in the subject term, can also be considered instances of superficial speech.

I end this paper with a worry that I hope I can dissolve. Distinguishing between lekta and pragmata seems to be an unnecessary inflation of the ontology of the Stoics, especially since the ontological status of pragmata is not addressed in the extant evidence. Although I have referred to pragmata as "items" or "entities" throughout this paper, we needn't conceive of pragmata as items or entities in any robust sense. They are items, or things, only in a deflationary sense - i.e. insofar as "Man is in Athens" expresses a pragma, something, whatever it may be, but not a lekton. If the lack of textual evidence discussing the ontological status of pragmata (including details about their nature and structure) is an indication of what the Stoics are interested in philosophically, then we might 
take their silence as a symptom of disinterest in the notion of meaning simpliciter.

If I am right about the account I have reconstructed here, then the theory of lekta is not intended primarily as a solution to questions about linguistic significance. Rather, it is a systematic response to puzzles that arise from the vast range of things that language is used to do, and the conditions under which those things are done. ${ }^{63}$

Sosseh Assaturian

The University of Texas at Austin

sossehassaturian@utexas.edu

\section{References:}

Editions of Primary Sources:

Busse, A. (1897). Ammonius, In Aristotelis de Interpretatione commentarium (Commentaria in Aristotelem Graeca). Prussian Academy Series. Berlin: Reimer.

Dorandi, T. (2013). Diogenes Laertius: Lives of Eminent Philosophers, Cambridge, New York, CUP.

Goetz, G. \& F. Schoell. (1910). M. Terenti Varronis De Lingia Latina quae supersunt. Leipzig: Teubner.

Hülser, K. (1987). Die Fragmente zur Dialektik der Stoiker: Neue Sammlung der Texte mit der deutscher Übersetzung und Kommentaren. 4 Bände. Stuttgart: Frommann-holzboog.

Marrone, L. (1997). "Le Questioni Logichi di Crisippo (PHerc 307).” Cronache Ercolanesi 27, pp. 83100.

Mau, J. \& H. Mutschmann. (1914-1961). Sexti Empirici opera, vols. 2 \& 3, 2 ${ }^{\text {nd }}$ ed., Leipzig, Teubner, 2, 1914; 3, 1961: 2: p. 3-429; 3: p. 1-177.

Rabe, H. (1931). Prolegomenon Sylloge, Rhetores Graeci. Volumen xiv: Prolegomenon Sylloge. (Bibliotheca Scriptorum Graecorum et Romanorum Tuebneriana).

Remnant, P. \& J. Bennett. (1996). Leibniz: New Essays on Human Understanding (Cambridge Texts in the History of Philosophy). Cambridge: Cambridge University Press.

Schenkle, H. (1916). Epictetus: Dissertationes Ab Arriano Digestae; Enchiridion. Leipzig: Teubner.

Usener, H. \& I. Radermacher. (1899-1929). Dionysii Halicarnasei quae exstant, De Compositione Verborum in vol. 5. Leipzig: Teubner.

Von Arnim, Hans. (1905). Stoicorum Veterum Fragmenta. 3 vols. In Aedibus B.G. Teubneri.

Walz, C. (1832-1836). Rhetores Graeci. Tubingen: Sumtibus J. C. Cottae.

Winkler, K. P. (1996). Locke: An Essay Concerning Human Understanding. Indianapolis: Hackett.

Secondary Literature:

Atherton, C. (1993). The Stoics on Ambiguity. Cambridge University Press.

Austin, J. L. (1975). How to Do Things with Words. Cambridge: Harvard University Press.

Ax, W. (1986). Laut, Stimme und Sprache: Studien zu drei Grundbegriffen der antiken Sprachtheorie. Göttingen: Vandenhoek and Ruprecht.

\footnotetext{
63 I am grateful to Jim Hankinson, Victor Caston, Tomas Albergo, and the audience at the 2020 Eastern Division Meeting of the APA for helpful feedback on earlier drafts of this paper. I am especially thankful to Vanessa de Harven and Rachel O'Keefe for many insightful discussions and detailed comments that improved this paper.
} 
Barnes, J. (1993). "Meaning, Saying, and Thinking," in Döring, K. and Ebert, T (eds.) Dialektiker und Stoiker: Zur Logik der Stoa und ihrer l'orläufer, Philosophie der Antike, 1. Stuttgart: F. Steiner.

Blank, D. L. (2014). Ammonius: On Aristotle On Interpretation 1-8. New York: Bloomsbury Academic.

Bobzien, S. (2002). "Chrysippus and the epistemic theory of vagueness." Proceedings of the Aristotelian Society 102(1):217-238.

Brittain, G. (2002). "Non-Rational Perception in the Stoics and Augustine," Oxford Studies in Ancient Philosophy 22: 253-308.

Bronowski, A. (2019a). The Stoics on Lekta: All There Is to Say. Oxford: Oxford University Press.

Bronowski, A. (2019b). "What is Wrong with Lekta? Ancient Critics of Stoic Logic and Language." Methodos: 19.

Caluori, D. (2018). "Aporia and the Limits of Reason and Language in Damascius," in George Karamanolis and Vasilis Politis (eds.) The Aporetic Tradition in Ancient Philosophy. Cambridge: Cambridge University Press. pp. 269-284.

de Harven, V. (2019). "Rational Impressions and the Stoic Philosophy of Mind," in ed. J. Sisko, History of Philosophy of Mind: Pre-Socratics to Augustine. New York: Acumen Publishing. pp. 214235.

Fögen, T. (2014). "Animal Communication," in Gordon Lindsay Campbell (ed.) The Oxford Handbook of Animals in Classical Thought and Life. Oxford: Oxford University Press.

Frede, M. (1987). "Stoics and Skeptics on Clear and Distinct Impressions," in Essays in Ancient Philosophy. Minneapolis: University of Minnesota Press.

Frede, M. (1994). "The Stoic Notion of a Lekton," in Stephen Everson (ed.) Language. Cambridge: Cambridge University Press. pp. 109-128.

Glidden, D. K. (1994). "Parrots, Pyrrhonists, and Native Speakers," in Stephen Everson (ed.) Language. Cambridge: Cambridge University Press. pp.129-148.

Graeser, A. (1982). "The Stoic Theory of Meaning" in Rist (ed.), The Stoics.

Hahm, D. E. (1977). The Origins of Stoic Cosmology. Ohio State University Press.

Hülser, K. (2012). "Pragmatics and the Idea of the Illocutionary in Stoic Language Theory," in Ricca Edmondson and Karlheinz Hülser (ed.) Politics of Practical Reasoning: Integrating Action, Discourse, and Argument. Plymouth: Lexington Books. pp. 31-45.

Ioppolo, A. (1990). "Presentation and Assent: A Physical and Cognitive Problem in Early Stoicism." The Classical Quarterly 40:433-49.

Kneale, W. and M. Kneale. (1962). The Development of Logic. Oxford: Oxford University Press.

Lesses, G. (1998). "Content, Cause, and Stoic Impressions." Phronesis 43: 1-25.

Long, A.A. (1971). "Language and Thought in Stoicism," in A.A. Long (ed.) Problems in Stoicism. New Jersey: Athlone Press. pp. 75-113.

Long, A.A. and D. Sedley. (1987) The Hellenistic Philosophers. 2 vols. Cambridge University Press: Cambridge.

Mates, B. (1961). Stoic Logic. Berkeley: University of California Press.

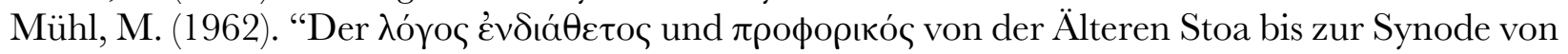
Sirmium 351" Archiv für Begriffsgeschichte 7: 7-56.

Nuchelmans, G. (1973). Theories of the Proposition: Ancient and Medieval Conceptions of the Bearers of Truth and Falsity. North-Holland Pub. Co.

Panaccio, C. (1999). Le discours intérieur: De Platon à Guillaume d'Ockham. Paris: Éditions du Seuil.

Pohlenz, M. (1939). "Die Begründung der abendländischen Sprachlehre durch die Stoa." Kleine Schriften I. Hildesheim: 79-86.

Schenkeveld, D.M. (1984). "Stoic and Peripatetic Kinds of Speech Act and the Distinction of Grammatical Moods." Mnemosyne 37: 291-252. 
Shogry, S. (2019). "What do our impressions say? The Stoic theory of perceptual content and belief formation." Apeiron 52(1): 29-63.

Smyth, H. W. (1920). Greek Grammar. Harvard.

Sorabji, R. (1990). "Perceptual Content in the Stoics." Phronesis 35: 307-14.

Vogt, K. M. (2012). "Appearances and Assent: Sceptical Belief Reconsidered.” Classical Quarterly 62: 648-663.

Williamson, T. (1994). Vagueness. London: Routledge. 